\title{
On the Wear Behavior of Cyanoacrylate in Presence of Nano-Sized $\mathrm{SiO}_{2}$
}

\author{
Amir Yaghmaei, Seyed Mojtaba Zebarjad*, Mehrdad Kashefi \\ Department of Materials Science and Metallurgical Engineering, Faculty of Engineering, \\ Ferdowsi University of Mashhad, Mashhad, Iran \\ Email: ${ }^{*}$ Zebarjad@um.ac.ir
}

Received October 20, 2011; revised January 4, 2012; accepted January 15, 2012

\begin{abstract}
Cyanoacrylate adhesive and its composites have been widely used in industry and dentistry. According to literature survey done by the authors, there are few papers concentrated on role of nano-sized particles on wear behavior of cyanoacrylate glue. Thus the main goal of current research focused on clarifying the role of nano-sized $\mathrm{SiO}_{2}$ on wear behavior of cyanoacrylate. Pin-on-disk wear test, SEM imaging and microhardness test was utilized to investigate wear performance of cyanoacrylate and its nanocomposites with $\mathrm{SiO}_{2}$. The results indicated that $\mathrm{SiO}_{2}$ nano powders can reduce wear rate of cyanoacrylate and change its wear mechanism. It was also shown that surface hardness of cyanoacrylate is increased by addition of nano-sized $\mathrm{SiO}_{2}$.
\end{abstract}

Keywords: Cyanoacrylate; $\mathrm{SiO}_{2}$ Nano Powders; Wear Behavior; SEM; Microhardness

\section{Introduction}

Polymer nanocomposites, have been widely employed to replace the traditional metals and ceramics in microelectronic packaging, coatings, aerospace, automotive, food packaging and biomedical applications. This is mainly because of their adequate strength, lightness, versatility, ease of processing and low cost [1]. By addition of lubricating and/or reinforcing fillers, the tribological properties of polymers are generally improved [2]. But using macro- and micro-composites have some limitations since the properties usually involve compromises [3,4], for example, stiffness and/or strength, important for scratch resistance, are achieved at the expense of toughness. One way to overcome this problem is to use fillers with particle size smaller than $100 \mathrm{~nm}$ the so called nano scale fillers. In fact using nano-particles can effectively improve the mechanical properties such as wear, hardness without weakening other properties [1,2].

Wear is a damage which happens by rubbing bodies due to repeated applications of mechanical, impact and other kinds of forces [5,6], involves several intrinsic and extrinsic factors. The Factors affecting wear rate of polymers are surface roughness, contact kinematics, nature of materials, mechanical, physical and chemical properties of interacting bodies, testing environment, etc. [1-11]. Wear mechanisms of polymers are still matter of controversy among investigators.

\footnotetext{
"Corresponding Author
}

Slide of two surfaces against each other can make welding in junctions (in case of polymers may include Van der Waals and hydrogen bonds) possibly due to heating at the interface [12]. This is the theory of adhesive wear in polymers that formation and rupture of the junctions control the adhesion component of friction $[7,8]$. Abrasive wear is the most common type of wear, particularly in polymer composites that can be sub-divided into two-body abrasion wear and three-body abrasion wear $[1,7,8]$. When hard asperities plow and cause plastic deformation or fracture of the softer ones, two-body abrasion wear occurs; on the other hand, when hard abrasive particles or wear debris are introduced into the sliding system either as environmental contaminants or as products of two-body abrasion, three-body abrasion wear occurs. The repeated stressing and un-stressing of the contacts eventually leading to fatigue wear in polymers $[7,8]$, for example epoxy resin can be fined when slides against a silicon nitride ball [13]. Other forms of wear damages such as delaminating wear [14] and transfer wear [15] are also reported for polymers but other forms of wear such as chemical, fretting, erosion, corrosion, etc are less common in polymers [16-19].

Fillers can improve tribological properties of polymers. One of the fillers that is used to reinforce polymers is $\mathrm{SiO}_{2}$. Because of its rigidity and high stability, nano sized silica powders have widely been used to improve properties of polymer matrix composite materials [20-22]. Su et al. [23] and Zhang et al. [24] have used $\mathrm{SiO}_{2}$ nano powders 
to improve wear resistance of carbon fabric composites. Guo et al. [25] and Zhang et al. [26] obtained that addition of nano- $\mathrm{SiO}_{2}$ reduces the wear rate of epoxy and Poly-ether-ether-ketone (PEEK) reinforced with short carbon fibers. Nano- $\mathrm{SiO}_{2}$ was used as filler for polyurethane by Jie Song et al. [27] to improve tribological behavior of polyurethane coating.

Cyanoacrylate is a solvent free, one part adhesive that is widely used in automotive indusries [28], electrical and electronic devices [29], fingerprinting [30,31], and medicine [21,32,33]. Like other polymers, fillers could be added to cyanoacrylate in order to improve its tribological properties. Modifiers such as alumina [34], calcium carbonate [35,36], hydroxyapatite [37,38] and silicon dioxide [39-41] are added to cyanoacrylate to promote its mechanical and physical properties. The present paper aims at filling the literature gap on wear behavior of cyanoacrylate in presence of nano-sized $\mathrm{SiO}_{2}$ particles.

\section{Materials and Methods}

\subsection{Materials}

Alkoxyethyl cyanoacrylate (Loctite 460, Henkel) with a viscosity of $45 \mathrm{mPa} . \mathrm{s}$ and silicon dioxide nano powders (Nanolin, China) were used as matrix and reinforcement respectively. $\mathrm{SiO}_{2}$ nano powders were polygonal in shape, 10-20 nm in size and with a purity of 99\%. Figure 1 shows the TEM micrograph of silicon dioxide nano powders. In order to prevent polymerization of cyanoacrylate by moisture and other electron donor materials [38, 42], acids are added to cyanoacrylate. In this research para-toluene solfunic acid (catalogue No. 814725, Merck) was utilized. Neutralization should take place before polymerization $[28,43]$ and for this purpose caffeine (catalogue No. 119164, Merck) was used in the current research.

\subsection{Sample Preparation}

To prepare nanocomposite samples, $1 \mathrm{wt} \%$ acid was solved in cyanoacrylate prior mixing with the nano-powder to act as an inhibitor. Without dissolving this level of acid, polymerization occurs immediately after mixing with nano-sized silicon dioxide powders. The reasons for the premature polymerization could be the presence of moisture on the surface of the powders as well as natural chemistry of the powders. In the next step, $1.5 \mathrm{wt} \%$ caffeine was added to the mixture for acid neutralization and as polymerization initiator. It is worth noting that without the presence of the caffeine, polymerization will be retarded for several days. Theses minimum levels of acid and caffeine were chosen after several experiments. Finally, different amounts of silicon dioxide were added in order to investigate the role of silicon dioxide nano powders in

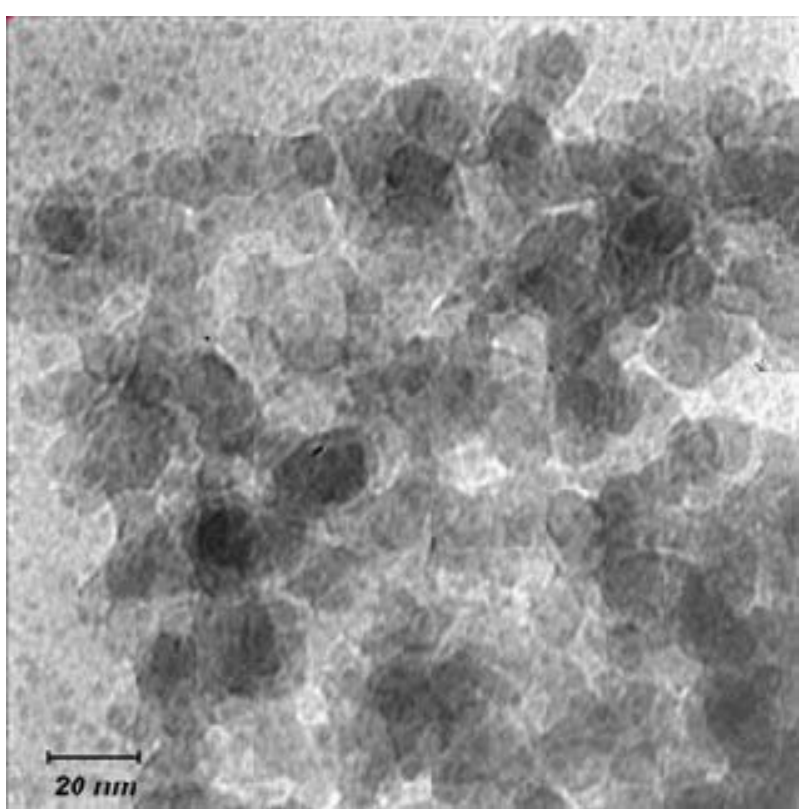

Figure 1. TEM micrograph of $\mathrm{SiO}_{2}$ nanopowders.

the nanocomposite. To prevent agglomeration of nanosized powders, they were milled by mixer mill device (Retsich MM400, Germany) for 10 minutes prior to mixing with cyanoacrylate. The specifications of all fabricated samples are summarized in Table 1.

A transmission electron microscope, LEO 919 AB, was used to observe both size and shape of nano size silicon dioxide powders. For sample preparation, powders were first mixer milled (Retsich MM400, Germany) for 10 minutes and then dispersed in ethanol and sonicated for 1 hour. Afterward, dispersed powders were placed on grid for taking photo.

\subsection{Wear Test}

The wear test method of pin-on-disk [44] was utilized inthis research. For each formulation (according to Table 1), 5 samples were tested. Each sample prepared with base area of $4 \mathrm{~mm}^{2}$ and $10 \mathrm{~mm}$ height which was attached to a removable sample holder with cyanoacrylate glue. In the current study a special wear devise was developed. The device was consisted of an aluminum holder that can freely move up and down. This character allows specimens to be under a certain force at all times during the tests. The device rotated one orbit per second

Table 1. The produced nanocomposites.

\begin{tabular}{ccccc}
\hline $\begin{array}{c}\text { Sample } \\
\text { name }\end{array}$ & $\begin{array}{c}\text { Polymer } \\
\text { content (wt\%) }\end{array}$ & $\begin{array}{c}\text { Acid content } \\
(\mathrm{wt} \%)\end{array}$ & $\begin{array}{c}\text { Caffeine } \\
\text { content }(\mathrm{wt} \%)\end{array}$ & $\begin{array}{c}\mathrm{SiO}_{2} \text { content } \\
(\mathrm{wt} \%)\end{array}$ \\
\hline $\mathrm{Cy} / 0 \% \mathrm{SiO}_{2}$ & 97.5 & 1 & 1.5 & 0 \\
$\mathrm{Cy} / 8 \% \mathrm{SiO}_{2}$ & 89.5 & 1 & 1.5 & 8 \\
$\mathrm{Cy} / 10 \% \mathrm{SiO}_{2}$ & 87.5 & 1 & 1.5 & 10 \\
$\mathrm{Cy} / 12 \% \mathrm{SiO}_{2}$ & 85.5 & 1 & 1.5 & 12 \\
\hline
\end{tabular}


and number of turns recorded digitally for each run. A brass cup with interior diameter of $26 \mathrm{~mm}$ was utilized as container of artificial saliva and as holder of abrasive plate $\left(\mathrm{Al}_{2} \mathrm{O}_{3}\right.$ abrasive plate with diameter of $25 \mathrm{~mm}$, Dedeco, \#309-0009). Figure 2 shows the used wear device. Each specimen was abraded by 2000 and 7000 orbits. Samples were weighted with the accuracy of $\pm 0.00001 \mathrm{~g}$ before and after testing. Two conditions were used for this test: 5cc Fusayama Meyer artificial saliva $[45,46]$ and atmosphere. After each 2000 and 7000 orbits, both saliva and abrasive plates were replaced.

For each formulation, 5 samples were tested. After each 2000 and 7000 orbits, samples weights were measured and wear rate was calculated by the following formula

Wear Rate $=\Delta W / L$

where $\Delta W$ is the difference of weight measurement before and after each 2000 and 7000 orbits and $L$ (in meter) is the distance for each 2000 and 7000 rotations and are calculated as follows,

$$
\begin{aligned}
& L_{2000}=2000 \times 2 \pi \mathrm{R}=125.6 \mathrm{~m} \\
& L_{7000}=7000 \times 2 \pi \mathrm{R}=439.6 \mathrm{~m}
\end{aligned}
$$

Xiaoqiang et al. [47] expressed that the chewing stress on occlusal surface of teeth is varying between $0.8-1.75$ $\mathrm{MPa}$. Thus in this research we used the force of $4 \mathrm{~N}$ to obtain $1 \mathrm{MPa}$ stress on specimens.

\subsection{Hardness Measurement}

In general, surface hardness is one of the most important factors that govern materials' wear resistance. Harder surface would have higher wear resistance [25]. Thus, hardness measurement was also performed. For hardness measurement, samples were first cold mounted by acrylic resin. Hardness of specimens was measured by microhardness test device (MicroMet 4, Buehler) and for each formulation 15 indentations were done. The Vickers hardness, $H_{v}$, is defined as the load divided by the surface area of the impression made by the indenter. The Vickers hardness was calculated using the mean of the two diagonal lengths of the indentation in the following formula:

$$
H_{v}=\frac{1.854 P}{d^{2}}
$$

where $P$ is the applied load (kgf) and $d$ is the mean indentation diagonal length $(\mathrm{mm})$.

\section{Results and Discussion}

\subsection{Wear Teat Results}

The results of wear tests in atmosphere are shown in Figure 3. It can be observed that wear rate decreases by increasing in $\mathrm{SiO}_{2}$ content. This is because of presence of ceramic powders of $\mathrm{SiO}_{2}$ which have high hardness that can im-

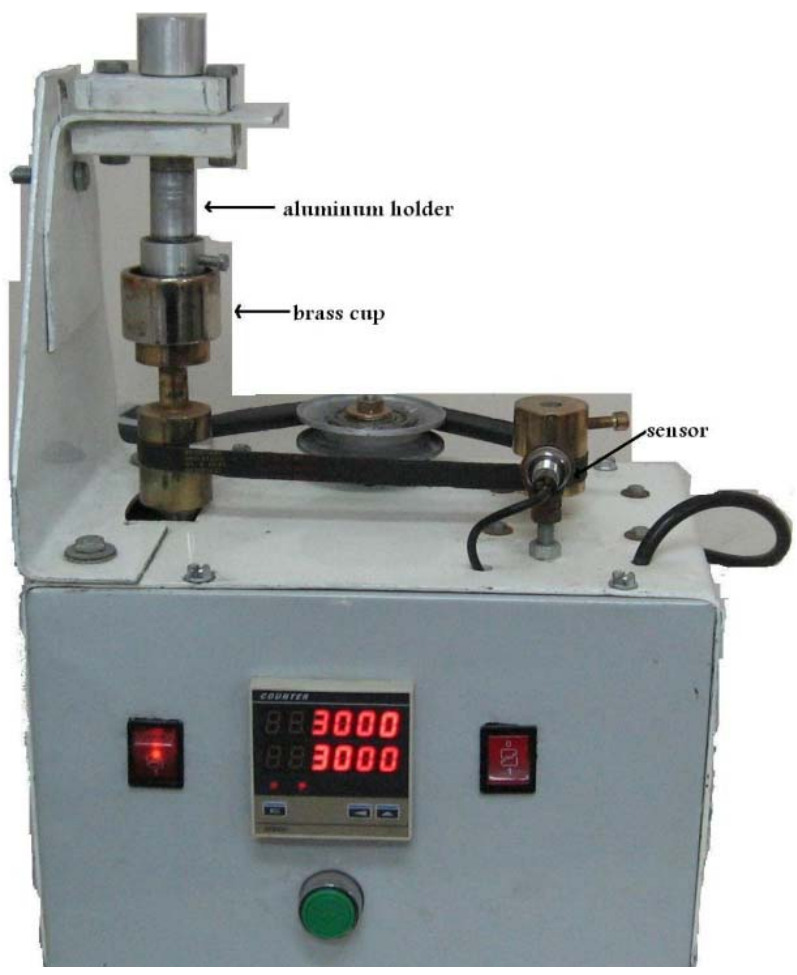

Figure 2. Wear device which was used.

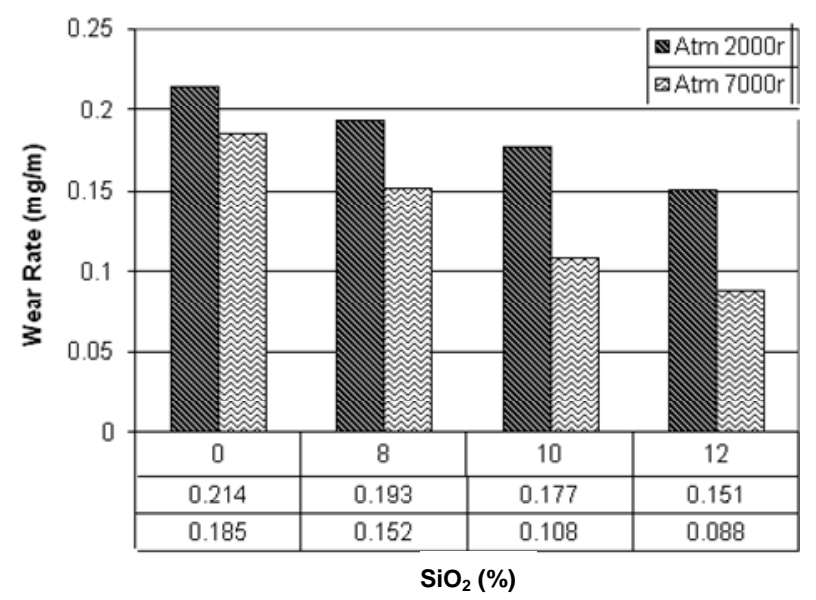

Figure 3. Wear test in atmosphere.

prove sliding wear rate [25]. This improvement in wear rates is more obvious for $\mathrm{Cy} / 8 \% \mathrm{SiO}_{2}$ comparing to pure cyanoacrylate, which emphasis the role of $\mathrm{SiO}_{2}$ in improvement of wear rate. For both 2000 and 7000 orbit this trend can be observed.

Figure 4 shows the results of wear test in FusayamaMeyer artificial saliva. As seen, the improvement in wear rate of cyanoacrylate at the presence of $\mathrm{SiO}_{2}$ nano powders is greater than atmospheric media. This is because of third body abrasion effect. Abraded particles act as an additional abrasive surface and cause more wear $[1,13$, 48]. In the mouth, this type of wear occurs during "mastication" and is prevalent in patients who eat abrasive 


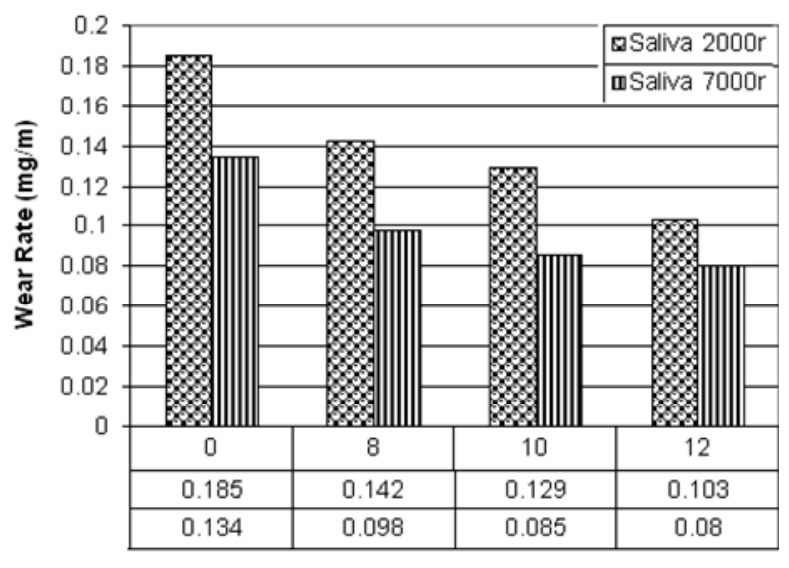

$\mathrm{SiO}_{2}(\%)$

Figure 4. Wear test in Fusayama Meyer artificial saliva.

diet such as grained bread. During the "early stage", when the occlusal surfaces are separated by the food bolus, the abrasive particles act as a slurry and abrade the whole surface [48]. In wet condition (saliva) the abraded particles are removed from the surface but it can not happen in dry condition (atmosphere). This is the reason for higher wear rate in atmosphere in comparison with saliva.

Figure 5 shows SEM micrographs of the worn surface of the specimens. For neat cyanoacrylate (Figure 5(a)), adhesive wear is the main mechanism responsible for material loss in the specimen. When nano- $\mathrm{SiO}_{2}$ is incorporated, the worn morphologies of the composites (Figures 5(b)-(d)) become less coarse and the wear mechanism is changed to abrasive wear. This is the main reason of improvement of wear resistance in presence of nanosized $\mathrm{SiO}_{2}$. It can be observed that there is no significant difference between SEM micrographs of three composites contain $8 \%-10 \%$ nano $\mathrm{SiO}_{2}$ which verifies the results in Figures 3 and 4. As it is clear there are some splinted wear debris in some regions and implies the role of third body on wear mechanism. Wang et al. [49] and Bragdon et al. [50] have shown the effect of third body on increasing of wear rate for highly cross-linked polyethylene. Pallav et al. [51] have also studied influence of third body on wear rate of amalgam which can increase it.

Figures 6 and 7 are comparisons between 2000 and 7000 rotations in saliva and atmospheric media. In both figures it can be observed that there is a higher wear rate in atmospheric media in comparison with saliva. As it was mentioned, this is because of more third body abrasion in atmospheric media than in saliva.

\subsection{Hardness Test Results}

The developing hardness of the cement formulations can be seen in Figure 8. Each data is the mean hardness

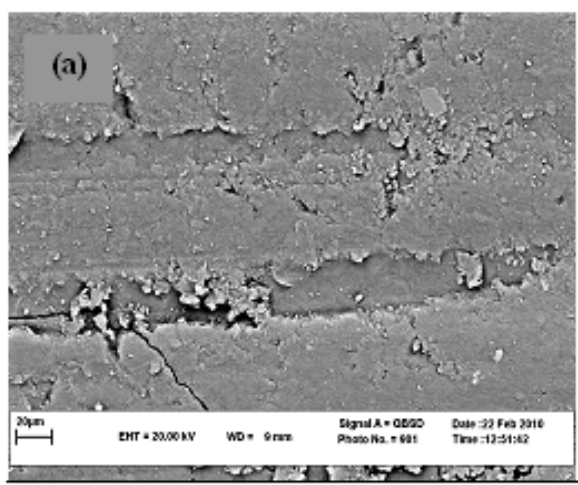

(a)

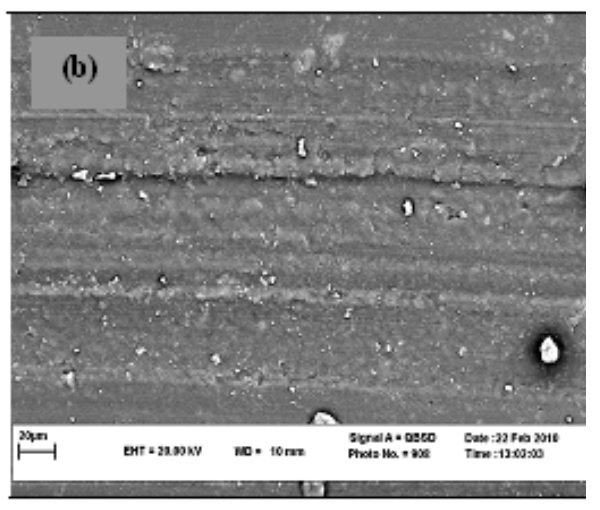

(b)

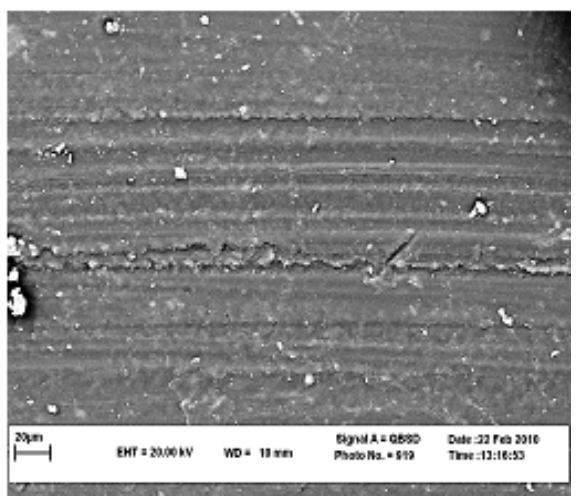

(c)

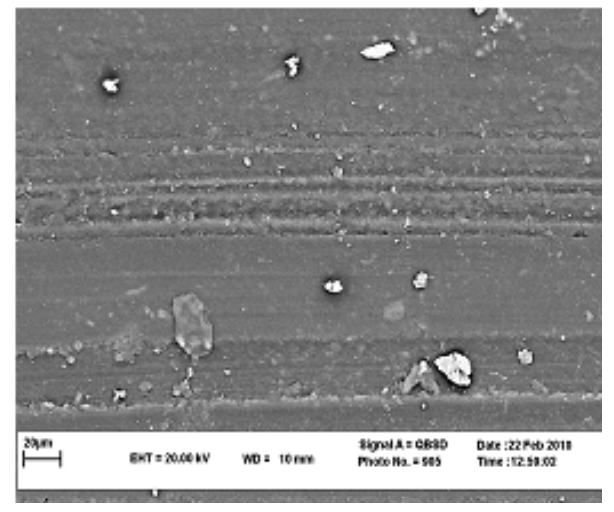

(d)

Figure 5. SEM micrograph of worn surfaces. 
calculated from fifteen indentations. It can be observed that the hardness of composite improves more than $40 \%$ by addition of $8 \% \mathrm{SiO}_{2}$ nano powders. The hardness improves gradually by addition of more powders but this improvement is not remarkable. This hardness development can be mainly because of [38]:

1) The ratio of cyanoacrylate and $\mathrm{SiO}_{2}$;

2) The hardness of $\mathrm{SiO}_{2}$ nano powders;

3) The bond strength achieved between $\mathrm{SiO}_{2}$ and cyanoacrylate.

As it was mentioned, one of the most important factors in wear resistance of materials is surface hardness. Therefore, this development in hardness can support the improvement of wear resistance that was achieved in this investigation.

\section{Conclusions}

Wear behavior of Cyanoacrylate in presence of nano-sized

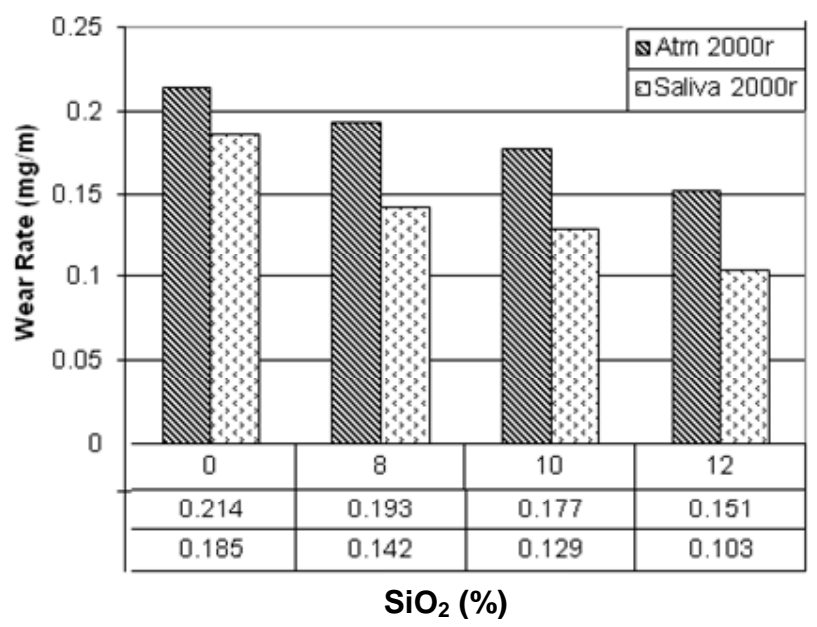

Figure 6. Comparison between Wear tests in Fusayama Meyer artificial saliva and atmosphere in 2000 orbits.

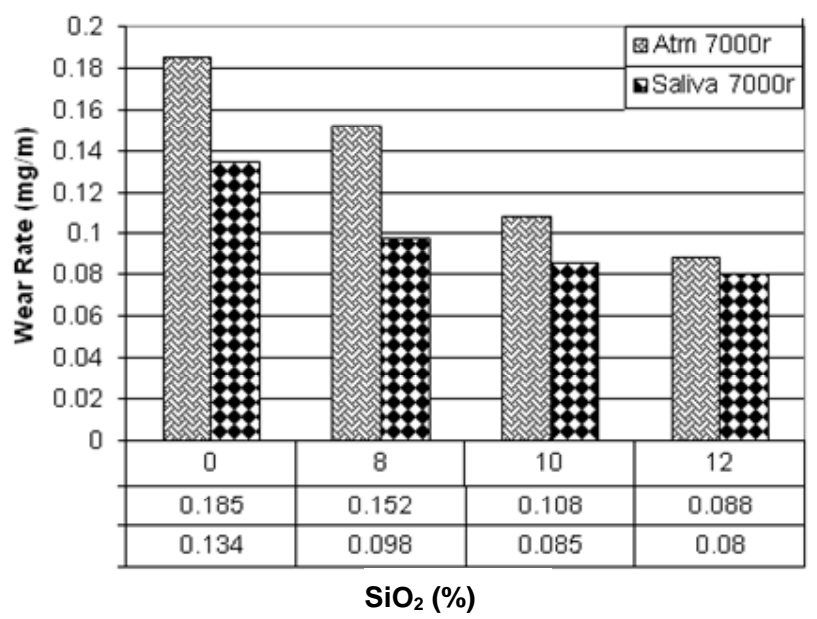

Figure 7. Comparison between Wear tests in Fusayama Meyer artificial saliva and atmosphere in 7000 orbits.

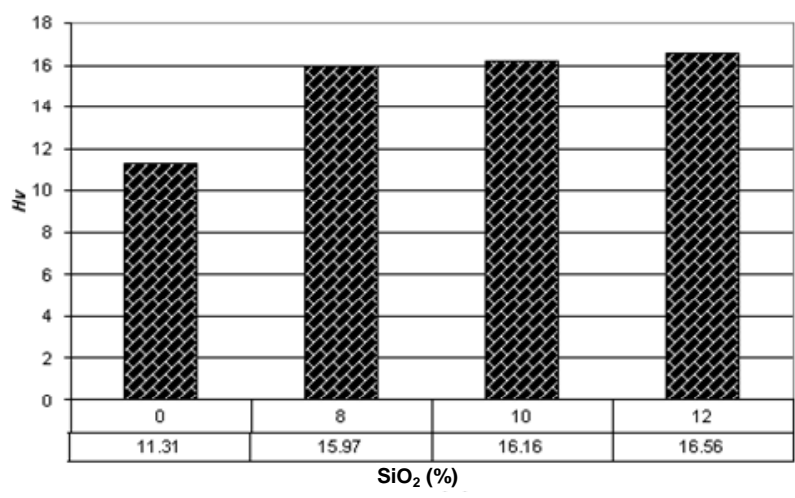

Figure 8. Data of hardness test.

$\mathrm{SiO}_{2}$ was investigated. Pin-on-disk test and microscopic evaluation were performed. The results are remarked:

1) $\mathrm{SiO}_{2}$ nano powders can reduce wear damage in cyanoacrylate;

2) SEM imaging shows that $\mathrm{SiO}_{2}$ nano powders can alter adhesive wear mechanism to abrasive wear;

3) $\mathrm{SiO}_{2}$ nano powders can also increase surface hardness of cyanoacrylate and that can improve wear performance of cyanoacrylate composites.

\section{Acknowledgements}

The authors would like to thank Iranian Nanotechnology Initiative Council (INIC) for their financial support and Central Laboratory of Ferdowsi University of Mashhad for their technical support of this research.

\section{REFERENCES}

[1] A. Dasari, Z. Z. Yu and Y. W. Mai, "Fundamental Aspect and Recent Progress on Wear/Scratch Damage in Polymer Nanocomposites," Materials Science and Engineering: R: Reports, Vol. 63, No. 2, 2009, pp. 31-80. doi:10.1016/j.mser.2008.10.001

[2] J. Song and G. W. Ehresntein, "Friction and Wear of Self-Reinforced Thermoplastics," In: K. Friedrich, Ed., Advances in Composite Tribology, Elsevier, Amsterdam, 1993, pp. 19-61.

[3] R. A. Vaia and R. Krishnamoorti, "Polymer Nanocomposites: Synthesis, Characterization, and Modeling," American Chemical Society, Washington DC, 2002.

[4] Z.-Z. Yu, A. Dasari and Y. W. Mai, "Polymer-Clay Nanocomposites-A Review of Their Mechanical and Physical Properties," In: S. G. Advani, Ed., Processing and Properties of Polymer Nanocomposites, World Scientific Publishers, Singapore, 2006, pp. 307-358. doi:10.1142/97898127724730007

[5] A. E. Anderson, "Friction Lubrication and Wear Technology,” ASM International, 1992.

[6] S. J. Kim, M. H. Cho, R. S. Basch, J. W. Fash and H. Jang, "Tribological Properties of Polymer Composites Containing Barite $\left(\mathrm{BaSO}_{4}\right)$ or Potassium Titanate $\left(\mathrm{K}_{2} \mathrm{O}_{6}\left(\mathrm{TiO}_{2}\right)\right)$," Tribology Letters, Vol. 17, No. 3, 2004, 
pp. 655-661. doi:10.1023/B:TRIL.0000044516.75340.25

[7] H. Czichos, "Introduction to Friction and Wear," In: K. Friedrich, Ed., Friction and Wear of Polymer Composites, Elsevier, 1986, pp. 1-22.

[8] G. M. Bartenev and V. V. Lavrentev, "Friction and Wear of Polymers," Elsevier, Amsterdam, 1981.

[9] L. Chang, Z. Zhang, C. Breidt and K. Friedrich, "Tribological Properties of Epoxy Nanocomposites: I. Enhancement of the Wear Resistance by Nano-TiO 2 Particles," Wear, Vol. 258, No. 1-4, 2005, pp. 141-148. doi:10.1016/j.wear.2004.09.005

[10] S. Bahadur and C. Sunkara, "Effect of Transfer Film Structure, Composition and Bonding on the Tribological Behavior of Polyphenylene Sulfide Filled with Nano Particles of $\mathrm{TiO}_{2}, \mathrm{ZnO}, \mathrm{CuO}$ and $\mathrm{SiC}$," Wear, Vol. 258, No. 9, 2005, pp. 1411-1421. doi:10.1016/j.wear.2004.08.009

[11] H. Jiang, R. Browning and H. J. Sue, "Understanding of Scratch-Induced Damage Mechanisms in Polymers," Polymer, Vol. 50, No. 16, 2009, pp. 4056-4065. doi:10.1016/j.polymer.2009.06.061

[12] B. J. Briscoe, B. H. Stuart, S. Sebastian and P. J. Tweedale, "The Failure of Poly (Ether Ether Ketone) in High Speed Contacts," Wear, Vol. 162-164, 1993, pp. 407-417. doi:10.1016/0043-1648(93)90524-P

[13] A. Dasari, "On Toughening and Wear/Scratch Damage in Polymer Nanocomposites," The University of Sydney, Sydney, 2007.

[14] N. P. Suh, M. Mosleh and J. Arinez, "Tribology of Polyethylene Homocomposites," Wear, Vol. 214, No. 2, 1998, pp. 231-236. doi:10.1016/S0043-1648(97)00233-0

[15] S. H. Rhee and K. C. Ludema, "Mechanisms of Formation of Polymeric Transfer Films," Wear, Vol. 46, No. 1, 1978, pp. 231-240. doi:10.1016/0043-1648(78)90124-2

[16] B. J. Briscoe, "Materials Aspects of Polymer Wear," Scripta Metallurgica et Materialia, Vol. 24, No. 5, 1990, pp. 839-844. doi:10.1016/0956-716X(90)90122-W

[17] P. A. Higham, F. H. Stott and B. Bethune, "The Influence of Polymer Composition on the Wear of the Metal Surface during Fretting of Steel on Polymer," Wear, Vol. 47, No. 1, 1978, pp. 71-80. doi:10.1016/0043-1648(78)90204-1

[18] M. S. ElTobgy, E. Ng and M. A. Elbestawi, "Finite Element Modeling of Erosive Wear," International Journal of Machine Tools and Manufacture, Vol. 45, No. 11, 2005, pp. 1337-1346.

doi:10.1016/j.ijmachtools.2005.01.007

[19] I. Finnie, "Some Reflections on the Past and Future of Erosion," Wear, Vol. 186-187, 1995, pp. 1-10. doi:10.1016/0043-1648(95)07188-1

[20] D. Li, Q. Liu, L. Yu, X. Li and Z. Zhang, "Correlation between Interfacial Interactions and Mechanical Properties of PA-6 Doped with Surface-Capped Nano-Silica," Applied Surface Science, Vol. 255, No. 18, 2009, pp. 7871-7877. doi:10.1016/j.apsusc.2009.04.121

[21] D. E. Setlik, D. L. Seldomridge, R. A. Adelman, T. M. Semchyshyn and N. A. Afshari, "The Effectiveness of Isobutyl Cyanoacrylate Tissue Adhesive for the Treatment of Corneal Perforations," American Journal of Oph- thalmology, Vol. 140, No. 5, 2005, pp. 920-921. doi:10.1016/j.ajo.2005.04.062

[22] D. C. Ritterband, S. W. Meskin, D. E. Shapiro, J. Kusmierczyk, J. A. Seedor and R. S. Koplin, "Laboratory Model of Tissue Adhesive (2-Octyl Cyanoacrylate) in Sealing Clear Corneal Cataract Wounds," American Journal of Ophthalmology, Vol. 140, No. 6, 2005, pp. 1039-1043. doi:10.1016/j.ajo.2005.06.055

[23] F. Su, Z. Zhang and W. Liu, "Mechanical and Tribological Properties of Carbon Fabric Composites Filled with Several Nano-Particulates," Wear, Vol. 260, No. 7-8, 2006, pp. 861-868. doi:10.1016/j.wear.2005.04.015

[24] Z. Zhang, F. Su, K. Wang, W. Ging, Z. Men and W. Liu, "Study on the Friction and Wear Properties of Carbon Fabric Composites Reinforced with Micro- and NanoParticles," Materials Science and Engineering: A, Vol. 404, No. 1-2, 2005, pp. 251-258. doi:10.1016/j.msea.2005.05.084

[25] Q. B. Guo, M. Z. Rong, G. L. Jia, K. T. Lau and M. Q. Zhang, "Sliding Wear Performance of Nano-SiO 2 /Short Carbon Fiber/Epoxy Hybrid Composites," Wear, Vol. 266, No. 7-8, 2009, pp. 658-665.

doi:10.1016/j.wear.2008.08.005

[26] G. Zhang, L. Chang and A. K. Schlarb, "The Roles of Nano-SiO ${ }_{2}$ Particles on the Tribological Behavior of Short Carbon Fiber Reinforced PEEK," Composites Science and Technology, Vol. 69, No. 7-8, 2009, pp. 10291035. doi:10.1016/j.compscitech.2009.01.023

[27] H. J. Song, Z. Z. Zhang and X. H. Men, "The Tribological Behaviors of the Polyurethane Coating Filled with Nano- $\mathrm{SiO}_{2}$ under Different Lubrication Conditions," Composites Part A: Applied Science and Manufacturing, Vol. 39, No. 2, 2008, pp. 188-194.

doi:10.1016/j.compositesa.2007.11.003

[28] J. S. Ridgway, J. B. Hull and C. R. Gentle, "A PRIME Approach for the Moulding of Conduit Ceramic Parts," Journal of Materials Processing Technology, Vol. 133, No. 1-2, 2003, pp. 181-188. doi:10.1016/S0924-0136(02)00229-7

[29] O. N. Klenovich and A. M. Vetrova, "Filled Cyanoacrylate Adhesive Compositions," Polymer Science Series C, Vol. 49, No. 1, 2007, pp. 50-51. doi:10.1134/S1811238207010110

[30] S. P. Wargacki, L. A. Lewis and M. D. Dadmun, "Enhancing the Quality of Aged Latent Fingerprints Developed by Superglue Fuming: Loss and Replenishment of Initiator," Journal of Forensic Sciences, Vol. 53, No. 5, 2008, pp. 1138-1144. doi:10.1111/j.1556-4029.2008.00822.x

[31] A. Gupta, K. Buckley and R. Sutton, "Latent Fingermark Pore Area Reproducibility," Forensic Science International, Vol. 179, No. 2-3, 2008, pp. 172-175. doi:10.1016/j.forsciint.2008.05.011

[32] G. A. Greenhill and B. O'Regan, "Incidence of Hypertrophic and Keloid Scars after N-butyl 2-Cyanoacrylate Tissue Adhesive Had Been Used to Close Parotidectomy Wounds: A Prospective Study of 100 Consecutive Patients," British Journal of Oral and Maxillofacial Surgery, Vol. 47, No. 4, 2009, pp. 290-293. 
doi:10.1016/j.bjoms.2009.01.011

[33] D. C. Ritterband, S. W. Meskin, D. E. Shapiro, J. Kusmierczyk, J. A. Seedor and R. S. Koplin, "Laboratory Model of Tissue Adhesive (2-Octyl Cyanoacrylate) in Sealing Clear Corneal Cataract Wounds," American Journal of Ophthalmology, Vol. 140, No. 6, 2005, pp. 1039-1043. doi:10.1016/j.ajo.2005.06.055

[34] J. S. Ridgway, J. B. Hull and C. R. Gentle, "Development of a Novel Binder System for Manufacture of Ceramic Heart Valve Prostheses," Journal of Materials Processing Technology, Vol. 109, No. 1-2, 2001, pp. 161-167. doi:10.1016/S0924-0136(00)00791-3

[35] F. Leonard and G. Brandes, "Under Water Adhesive Process," US Patent 3607542, 1971.

[36] S. Cijvan, P. M. Margetis and R. L. Reddick, "Properties of n-Butyl- $\alpha$-cyanoacrylate Mixtures," Journal of Dental Research, Vol. 48, No. 4, 1969, pp. 536-542.

[37] A. J. Bennetts, C. G. Wilde and A. D. Wilson, "Adhesive Cement," UK Patent 2386121, 2003.

[38] S. K. Tomlinson, O. R. Ghita, R. M. Hooper, K. E. Evans, "Monomer Conversion and Hardness of Novel Dental Cements Based on Ethyl Cyanoacrylate," Dental Materials, Vol. 23, No. 7, 2007, pp. 799-806. doi:10.1016/j.dental.2006.06.027

[39] M. Takeuchi and A. Otsuki, "Adhesive Pit and Fissure Sealant," US Patent 4012840, 1977.

[40] J. Suffner, G. Schechner, H. Sieger and H. Hahn, "In-Situ Coating of Silica Nanoparticles with Acrylate-Based Polymers," Chemical Vapor Deposition, Vol. 13, No. 9, 2007, pp. 459-464. doi:10.1002/cvde.200606522

[41] D. J. Boday, K. A. DeFriend, K. V. Wilson Jr., D. Coder and D. A. Loy, "Formation of Polycyanoacrylate/Silica Nanocomposites by Chemical Vapor Deposition of Cyanoacrylates on Aerogels," Chemistry of Materials, Vol. 20, No. 9, 2008, pp. 2845-2847. doi:10.1021/cm703381e

[42] H. G. M. Edwards and J. S. Day, "Fourier Transform Raman Spectroscopic Studies of the Curing of Cyanoacrylate Glue," Journal of Raman Spectroscopy, Vol. 35, No. 7, 2004, pp. 555-560. doi:10.1002/jrs.1184

[43] C. Birkinshaw, M. Buggy and A. O'Neill, "Reaction
Moulding of Metal and Ceramic Powders," Journal of Chemical Technology and Biotechnology, Vol. 66, No. 1, 1996, pp. 19-24. doi:10.1002/(SICI)1097-4660(199605)66:1<19::AID-JCT B458>3.3.CO;2-C

[44] R. Jacobi, H. T. Shillinbury and M. G. Dencanson, “A Comparison of the Abrasiveness of Six Ceramic Surfaces and Gold," The Journal of Prosthetic Dentistry, Vol. 66, No. 3, 1991, pp. 303-309. doi:10.1016/0022-3913(91)90254-T

[45] J. M. Meyer and J. N. Nally, "Influence of Artificial Salivas on the Corrosion of Dental Alloys," Journal of Dental Research, Vol. 54, 1975, pp. 678-681.

[46] T. Fusayama, T. Katayori and S. Nomoto, "Corrosion of Gold and Amalgam Placed in Contact with Each Other," Journal of Dental Research, Vol. 42, 1963, pp. 11831197. doi:10.1177/00220345630420051301

[47] H. U. Xiaqiang, P. M. Marquis and A. C. Shortall, "Two Body in Vitro Wear Study of Some Current Dental Composites and Amalgam," Journal of Prosthetic Dentistry, Vol. 82, No. 2, 1999, pp. 214-220. doi:10.1016/S0022-3913(99)70159-9

[48] L. H. Mair, "Wear in the Mouth: The Tribological Dimension," In: M. Addy, G. Embery, W. M. Edgar and R. Orchardson, Eds., Tooth Wear and Sensitivity, Clinical Advances in Restorative Dentistry, Martin Dunitz Ltd., London, 2000, pp. 181-188.

[49] A. Wang and G. Schmidig, "Ceramic Femoral Heads Prevent Runaway Wear for Highly Crosslinked Polyethylene Acetabular Cups by Third-Body Bone Cement Particles," Wear, Vol. 255, No. 7-12, 2003, pp. 1054-1063.

[50] C. R. Bragdon, M. Jasty, O. K. Muratoglu, D. O. O'Connor and W. H. Harris, "Third-Body Wear of Highly Cross-Linked Polyethylene in a Hip Simulator," The Journal of Arthroplasty, Vol. 18, No. 5, 2003, pp. 553-561. doi:10.1016/S0883-5403(03)00146-3

[51] P. Pallav, A. J de Gee, A. Werner and C. L. Davidson, "Influence of Shearing Action of Food on Contact Stress and Subsequent Wear of Stress-Bearing Composites," Journal of Dental Research, Vol. 72, No. 1, 1993, pp. 56-61. doi:10.1177/00220345930720010801 